*Mestrando em Direito pela Pontifícia Universidade Católica de Minas Gerais

E-mail:_ehobarbosa@gmail. com

**Doutora em Direito pela Universidade Federal de Minas Gerais

Professora da Graduação e do Programa de Pós-graduação em Direito na Pontifícia Universidade Católica de Minas Gerais

E-mail: taisamacena@yahoo.com. br

***Mestrando em Direito pela Pontifícia Universidade Católica de Minas Gerais

E-mail: mariaclarasalencar@, gmail.com

\section{A ERA DAS CRIPTOMOEDAS E O DIREITO SUCESSÓRIO: REFLEXOS NA (IN) TRANSMISSIBILIDADE DO PATRIMÔNIO}

\author{
THE AGE OF CRYPTOCURRENCIES AND \\ INHERITANCE LAW: REFLECTIONS ON THE (NON) \\ TRANSFERABLE OF HERITAGE
}

\section{Eduardo Henrique de Oliveira Barbosa* Taisa Maria Macena de Lima** Maria Clara Souza Alencar***}

Como citar: BARBOSA, Eduardo Henrique de Oliveira; LIMA, Taisa Maria Macena de; ALENCAR, Maria Clara Souza. A era das criptomoedas e o direito sucessório: reflexos na (in) transmissibilidade do patrimônio. Scientia luris, Londrina, v. 25, n. 3, p. 49-70, nov. 2021. DOI 10.5433/21788189.2021v25n3p49. ISSN: $2178-8189$.

Resumo: As tecnologias vêm sendo desenvolvidas com uma evolução pioneira, nunca antes experimentada pela sociedade. Conforme surgem e impactam a população, precisam ser reguladas pelos países, evitando prejuízos a terceiros, em razão da omissão legislativa. Acerca do tema, aborda-se as principais características das criptomoedas; como estão sendo tratadas e reguladas por outros países; sua relação com o direito sucessório brasileiro; seus reflexos na legítima; os impasses da herança digital e assuntos correlatos. Como metodologia, utiliza-se o método teórico exploratório. Diante da recente criação das criptomoedas, muitos dispositivos legislativos ainda precisam ser alterados para que se adéquem à nova realidade. Exemplo do exposto é o direito sucessório brasileiro, que não possui dispositivos com o fim de regular a transferência patrimonial expressa em criptomoedas, uma realidade vivida por vários brasileiros. Ademais, destaca-se que o patrimônio em criptomoeda é apenas uma modalidade de herança digital, não atendida pela legislação, que se apresenta obsoleta. Percebe-se que uma atualização legal se faz necessária, para que as leis correspondam à realidade fática vivida pela população. É imprescindível que se estude as novas tecnologias: entender as criptomoedas é a única ferramenta eficaz contra a desinformação e as distorções sobre a temática, que é uma realidade do mundo contemporâneo.

Palavras-chave: Bitcoin. Criptomoeda. Direito sucessório. Droit de saisine. Legítima. 


\begin{abstract}
Technologies have been developed with a pioneering evolution, never experienced by society. As they arise and impact the population, they need to be regulated by countries, avoiding harm to third parties, due to legislative omission. The main characteristics of cryptocurrencies are addressed; how they are being treated and regulated by other countries; its relationship with Brazilian succession law; its reflexes in the legitimate one; the impasses of digital inheritance and related issues. It was used the exploratory theoretical method. In view of the recent creation of cryptocurrencies, many legislative provisions still need to be changed to adapt to the new reality. An example is the Brazilian inheritance law, which has no provisions to regulate the transfer of assets expressed in cryptocurrencies, a reality experienced by several Brazilians. Furthermore, it should be noted that cryptocurrency assets are only a form of digital inheritance, not covered by legislation, which is obsolete. It is noticed that a legal update is necessary, so that the laws correspond to the factual reality experienced by the population. It is essential to study new technologies: understanding cryptocurrencies is the only effective tool against misinformation and distortions on the subject, which is a reality in the contemporary world.
\end{abstract}

Keywords: Bitcoin. Cryptocurrency. Droit de saisine. Legitimate. Succession law. 


\section{INTRODUÇÃO}

A busca incessante por melhorias inseriu o mundo em uma constante evolução tecnológica. Em razão disso, novos inventos são disponibilizados à população a cada dia. Fruto dessa evolução, surgiram as criptomoedas, que permitem a movimentação de valores de forma direta entre pessoas, com segurança e rapidez, sem que instituições robustas - como os bancos - precisem validar tais transações.

Nesse movimento contínuo de evolução, é comum que surjam incertezas acerca das novas tecnologias, principalmente em razão da escassa regulamentação. Com as moedas digitais não foi diferente, no entanto, as inseguranças iniciais foram vencidas pelas variadas vantagens por elas apresentadas.

Diante da importância que as criptomoedas assumiram na sociedade, este artigo esclarecerá suas principais características; a forma com que são tratadas em diversos países; como se deu o processo regulatório das mesmas e o modo como se relacionam com o direito sucessório do Brasil, principal tema tratado neste artigo. Como metodologia, será utilizado o método teórico exploratório.

É notório que o direito sucessório, ainda que tenha sido fundamentalmente alterado para se amoldar as novas configurações familiares, na recodificação do direito civil (com o Código Civil de 2002), esteja em descompasso com novas nuances - como é o caso da herança de bens digitais. É comum o uso para estudo, referência e construção de pensamento doutrinas clássicas, que versam sobre os pensamentos do século $\mathrm{XIX}^{1}$, para explicar e exemplificar temáticas sucessórias contemporâneas.

Com o advento da tecnologia, o direito, por óbvio, não sairá ileso de tais transformações. No âmbito sucessório, a surpresa - e o desafio - adveio do surgimento de bens imateriais digitais. Passou a existir, então, a herança digital.

Nesse contexto - mas não só - encontram-se as supramencionadas criptomoedas. A era das moedas digitais, iniciada com o bitcoin, demarca um novo momento do direito sucessório: os bens patrimoniais não são mais palpáveis, quiçá transmissíveis. Seria, então, um desafio frente aos princípios clássicos das sucessões?

Há a problemática que decorre da transmissão das moedas virtuais, a começar pela própria questão da transmissibilidade e aplicabilidade do princípio de Droit de Saisine.

Ao longo desse artigo, abordar-se-á algumas questões atinentes a isto, principalmente no que tange à relação entre a transmissibilidade das criptomoedas e a (não) rastreabilidade, o que, por vezes, pode acarretar em uma possível mutação na ordem de vocação hereditária e, por consequência, em potencial afronta ao instituto secular da legítima.

Pretende-se, ao longo da exposição, não só apresentar novos conhecimentos e expandir

1 Como exemplos, cita-se doutrinadores como Pontes de Miranda e Carlos Maximiliano Pereira dos Santos, além do historiador Numa Denis Fustel de Coulanges. Ressalta-se que a obra de todos os citados, bem como de demais clássicos do direito e da história são excepcionais e fontes insubstituíveis de conhecimento. Todavia, conforme se defende ao longo do artigo, percebe-se a necessidade de atualização do conhecimento sobre o direito sucessório, uma vez que este não vem acompanhando as mudanças temporais. 
A ERA DAS CRIPTOMOEDAS E O DIREITO SUCESSÓRIO: REFLEXOS NA (IN)TRANSMISSIBILIDADE DO PATRIMÔNIO

os conceitos multidisciplinares que abordam a temática, mas também expandir os conceitos prédeterminados e ensinados pela ordem jurídica sucessória, demonstrando que o direito tem que se movimentar, para acompanhar a demanda atual e tecnológica das heranças digitais.]

\section{A TRANSDISCIPLINARIDADE COMO REALIDADE: INTERSEÇÃO ENTRE O DIREITO SUCESSÓRIO E AS CRIPTOMOEDAS}

À primeira vista pode parecer peculiar a escolha da temática. Todavia, as criptomoedas refletem uma realidade que já chegou ao mundo contemporâneo e o direito tem que acompanhar os novos paradigmas.

Dentro do direito, muitos seriam os aspectos relevantes para se tratar sobre as moedas digitais - as questões tributárias, por exemplo, são urgentemente necessárias. Entretanto, a herança de bens digitais também é um tema que envolve diversas nuances multidisciplinares e que pugna por respaldo jurídico-científico.

Carlos Antônio Leite Brandão, sobre as necessidades do mundo contemporâneo, ressalta que "A primeira das razões da transdisciplinaridade exigida hoje é o caráter e a amplitude dos desafios que o novo século nos apresenta. São problemas complexos e radicais que emergem e se exacerbam tanto no mundo acadêmico como fora dele [...]” (BRANDÃO, 2008, p. 19).

A importância de se estudar o impacto das criptomoedas no direito sucessório, conforme ver-se-á adiante, decorre das questões que envolvem os dois temas - conforme pode-se depreender, já, dos títulos das seções. Calânico Sobrinho Rios (2018, p. 202) pontua que

Não se pode perder de vista que esse entrelaçamento, interdisciplinar, [...] nada mais é do que o vínculo que liga Direito e Economia, em consonância com o que externa esse artigo. E, em direção a esse norte, tem-se que se estar diante da Análise Econômica do Direito e não apenas tratando de Direito stricto sensu. Como é sabido, Direito e AED são duas disciplinas distintas, mas, por tudo que foi apontado, sobretudo daquilo que se pode extrair da paralela noção aqui desenhada e que permeia a Análise Econômica do Direito e a legítima, a conclusão é óbvia. Os dois temas estão umbilicalmente ligados.

Necessário, porém, deixar claro que as peculiaridades de cada seara serão preservadas no presente trabalho - inclusive, por isto, a escolha de em um primeiro momento explanar sobre as características das moedas digitais e os aspectos legais atinentes, para em um momento posterior explicitar os problemas no campo do direito das sucessões.

Sobre o assunto, ressalta-se o indicado por Pietro Perlingieri (2002, p. 55), no sentido de que

O fracionamento da matéria jurídica e do ordenamento em ramos tem um sentido porque divide por competências e por necessidade de exposição uma matéria única em si mesma, mas não deve significar que a realidade do ordenamento é divisível em diversos setores dos quais um é totalmente autônomo em relação ao 
outro, de tal modo que possa ser proclamada a sua independência.

Diante da breve introdução acerca da importância transdisciplinar de se tratar da temática das moedas virtuais e do direito sucessório, perpassando pela herança de bens digitais, principalmente, dá-se seguimento à temática.

\section{CRIPTOMOEDAS - CONCEITO E EXEMPLOS}

O surgimento do termo criptomoeda se deu em 2008, quando o pseudônimo Satoshi Nakamoto (2008), que se acredita ser um programador ou grupo de programadores, divulgou o artigo "Bitcoin: A Peer-to-Peer Electronic Cash System" em fórum público. Apesar da divulgação do artigo ter ocorrido em 2008, apenas em 2009 a primeira criptomoeda foi disponibilizada e recebeu o nome de bitcoin.

O termo criptomoeda é assim definido por Nicole Fobe:

Criptomoedas são instrumentos monetários virtuais na medida em que não existem fisicamente. Sua emissão e posterior circulação são feitas integralmente via ciberespaço (motivo pelo qual essas moedas são também consideradas 'digitais'), por meio de programas open source, sendo o acesso à internet imprescindível (FOBE, 2016, p. 53, grifo nosso ou do autor??).

Uma importante característica das criptomoedas pode ser retirada da definição apresentada por Nicole Fobe: a utilização de programas open source. Um programa open source não restringe sua atualização e/ou modificação aos seus criadores, pelo contrário, concede tais ações a todos os seus usuários, que terão a importante tarefa de garantir o bom desenvolvimento das criptomoedas, permitindo a esses a realização de melhorias (FOBE, 2016, p. 21).

As criptomoedas foram desenvolvidas com a mesma ideia de finitude que perpassa a extração de metais e pedras preciosas no planeta. Por essa razão, termos ligados à mineração são comumente utilizados para se referir aos procedimentos realizados na busca por novas criptomoedas. Como exemplo, o termo "mina" refere-se ao maquinário utilizado para encontrar criptomoedas; "mineradores" são os operadores das minas; e "mineração" é o processo de busca por novas criptomoedas.

Conforme novas criptomoedas são encontradas, os problemas matemáticos tornam-se cada vez mais difíceis de serem solucionados. Assim como as jazidas minerais, a cada diamante retirado do solo haverá um diamante a menos para ser encontrado, tornando ainda mais árduo o trabalho a ser desenvolvido pelos próximos mineradores. Esse mecanismo é utilizado como uma forma de evitar a inflação em uma determinada criptomoeda, mantendo estável o seu valor. 2 Tradução livre: "Bitcoin: um sistema de pagamento eletrônico ponto a ponto". 
Segundo Jerry Brito e Andrea Castillo (2013, p. 7):

The arbitrary number chosen to be the cap is 21 million bitcoins. Miners are projected to painstakingly harvest the last 'satoshi', or 0.00000001 of a bitcoin, in the year 2140. If the total mining power scales to a high enough level, the difficulty in mining bitcoins will have increased so much that procuring this last satoshi will be quite a challenging digital undertaking ${ }^{3}$.

Após a descoberta do último "satoshi", correspondente a 0.00000001 de 1 bitcoin, que é a menor parte de um bitcoin, os mineradores não terão mais bitcoins a minerar. Para manter a constante solução de problemas matemáticos dos novos blocos, a remuneração desses se restringirá à porcentagem das transações registradas em um novo bloco, cujo problema matemático tenha sido solucionado.

Outra característica relevante das criptomoedas é que não possuem um órgão centralizador, como ocorre comumente com as moedas tradicionais, cujo poder de emissão está restrito ao Estado e é exercido por esse conforme a situação econômica de um país. A emissão de uma criptomoeda ocorre de forma diferente, por meio do processo de mineração, sem qualquer interferência estatal.

As transações realizadas com bitcoin também são efetivadas de forma específica. Em razão da inexistência de um órgão ou entidade responsável pela validação das transações, que ocorrem de uma pessoa para a outra com interferência reduzida de terceiros, duas vantagens foram atingidas. A primeira delas refere-se ao baixo custo da operação, que por envolver menos intermediários, reduz, na mesma proporção, o percentual a ser pago a esses. A segunda vantagem relaciona-se ao tempo gasto para validação da transação que, independentemente da distância entre os envolvidos, ocorrerá em média em dez minutos.

Apesar da moeda bitcoin ser a criptomoeda mais famosa da atualidade, várias outras foram desenvolvidas desde a sua criação. Segundo o site Coinlib, especialista em "provides live and historic cryptocurrency prices, portfolio, alerts, news, charts and detailed coin data", consultado no dia 11 de junho de 2020, existem cerca de 6.180 criptomoedas. (COINLIB, 2020)

Dentre as mais conhecidas, é possível citar Bitcoin, Ethereum, XRP, Tether e Bitcoin Cash. Apesar do número assustador de criptomoedas, não significa que todas possuem ou possuirão a mesma aceitabilidade do Bitcoin. Grande parte dessas moedas não sobreviverão e em breve não terão valor ou importância considerável no mercado das criptomoedas.

3 Tradução livre: “O número arbitrário escolhido para ser o limite é de 21 milhões de bitcoins. Projeta-se que os mineradores colham meticulosamente o último "satoshi", ou 0,00000001 de um bitcoin, no ano de 2140 . Se o poder total de mineração subir para um nível alto o suficiente, a dificuldade em minerar bitcoins aumentará tanto que a aquisição desse último satoshi será um empreendimento digital bastante desafiador”.

4 Tradução livre: “fornece preços ao vivo e históricos de criptomoedas, portfólio, alertas, notícias, gráficos e dados detalhados sobre moedas". 


\subsection{LIBERDADE MONETÁRIA, INTANGIBILIDADE E A REVOLUÇÃO FINANCEIRA： A ERA BITCOIN}

Os mecanismos utilizados pela sociedade como forma de pagamento e moeda sofreram constantes e importantes mudanças ao longo do tempo. Ao analisar a evolução histórica das moedas é possível perceber que o mundo, como se conhece hoje, não seria possível se o escambo ainda fosse a principal prática comercial utilizada, em que bens excedentes de uma família são trocados com os excedentes de outras famílias.

Característica de tempos mais recentes, também é difícil imaginar pagamentos com mercadorias utilizadas como moedas. Imagine a aquisição de imóveis e indústrias com valores fixados em milhões, quitados por meio de animais, como gado ou outro qualquer. Seriam necessários pátios imensos para armazenar o "pagamento", ou melhor, o "pagamento" que restar, uma vez que por serem animais, estão sujeitos à depreciação constante.

Após muito estudo e evolução, criou-se a moeda que se tem hoje, grafada em papel específico; com valor determinado e com tamanho diferenciado. Mecanismos utilizados com o fim de evitar sua cópia e emissão irrestrita, problemas que foram superados ao longo do tempo. Hoje, a moeda representa importante papel na sociedade.

Fernando Ulrich (2014, p. 100) afirma que o "dinheiro não é um mal; é, na verdade, o bem fundamental em qualquer economia minimamente complexa. [...] Em definitivo, o dinheiro é uma das instituições mais essenciais de uma civilização; é o bem que torna possível a cooperação social em larga escala".

Apesar dos importantes avanços presentes na história da moeda, ainda existem problemas que precisam ser solucionados. O principal deles é também o mais comum: a emissão irrestrita de moeda pelo governo. Diante de gastos que extrapolam as reservas públicas, governantes aplicam a prática usual de injetar novas cédulas na sociedade, desse modo, a dívida pode ser quitada sem que seja necessário aumentar a cobrança de impostos.

Com a inclusão de novas cédulas no mercado a economia é profundamente impactada, como esclarece Fernando Ulrich (2014, p. 105):

Há ganhadores e perdedores, nem sempre perfeitamente identificados. Enriquecem aqueles que primeiro recebem a moeda recém-criada, porque são capazes de adquirir bens e serviços aos preços ainda correntes. Estes são os recipientes mais próximos do dinheiro novo, como políticos, servidores públicos e as empresas dos setores ora beneficiados pelo gasto público. Empobrecem aqueles que por último recebem a moeda de nova criação, porque, após ela circular pela economia, o aumento da oferta monetária conduzirá necessariamente a uma diminuição no seu poder de compra, ou, o seu corolário, a uma elevação generalizada dos preços.

Se bem observado, é o trabalhador assalariado que sofrerá o maior impacto com a instabilidade econômica causada, já que seu salário não sofrerá reajustes na mesma proporção 
que o valor dos bens, serviços e produtos que precisará consumir. Consequência da inflação é o agravamento da desigualdade social existente entre os cidadãos e anos de luta para que o país volte ao status quo, com uma economia equilibrada.

Ao permitir que a emissão de moeda esteja atrelada à vontade de um governante, que pode exigir a emissão para pagar os gastos de seu governo, o país estará sujeito à inflação. A solução que se mostra simples, retirar tal prerrogativa dos governantes, parece demasiadamente improvável, afinal, esta é uma ótima escapatória para solucionar a ausência de moderação nos gastos públicos e uma lei nesse sentido precisaria da anuência do principal prejudicado, o governante, para entrar em vigor.

Frente à necessidade de se ter uma moeda desvinculada da vontade estatal, a moeda bitcoin apresenta avanços consideráveis nesse sentido. Nas palavras de Fernando Ulrich (2014, p. 105):

Precisamente neste ponto jaz uma das forças do Bitcoin. Ao invés de implorar pelo respaldo legal, ele o contorna. Ao invés de pedir permissão para operar, ele simplesmente existe. O Bitcoin não é uma criatura do estado, é uma invenção e evolução do mercado que independe do consentimento do poder público. É claro que as decisões políticas podem influenciar a conduta dos indivíduos e das empresas, mas aquelas, por si só, são incapazes de coibir o livre funcionamento da moeda digital.

Sabe-se que a moeda bitcoin apresenta certo risco, ainda, é possível que seus valores sofram abruptas variações, como ocorrido desde sua criação. Contudo, por ser desvinculada da vontade estatal, o bitcoin proporciona importante evolução no ramo. Contribui significativamente para que se tenha uma moeda neutra, que atenderá às exigências do comércio e não de um político ou partido. Em razão de sua existência recente, é provável que problemas relacionados às inconstâncias sejam minimizados com o tempo.

\section{REGULAÇÃO E LEGISLAÇÃO DAS CRIPTOMOEDAS}

Sabe-se que o direito está sempre um passo atrás das evoluções perceptíveis no mundo. Em regra, a existência de algo não depende de sua regulamentação, que comumente ocorre após sua criação. Conforme o lapso temporal existente entre descobertas ou invenções humanas se reduz, menor é o tempo disponível para que ela seja corretamente regulamentada.

Diante do surgimento e rápida propagação das criptomoedas em escala mundial, nenhum país estava preparado, de imediato, para a regulamentação do bitcoin. Não haviam legislações estrangeiras que poderiam ser importadas, ou mesmo utilizadas como parâmetros para a segura 
regulamentação interna. Desse modo, com o esforço individual realizado pelos países, três principais formas de se lidar com a moeda bitcoin puderam ser percebidas. Segundo Nicole Fobe, em um grupo de países, houve um simples reconhecimento da existência da criptomoeda, o que causou impactos pontuais na legislação interna do mesmo, que passou a prever tributação e, em alguns casos, ampliou a incidência de certas normas, como as normas penais. Neste mesmo grupo, percebeu-se a inexistência de debate jurídico acerca do caráter monetário do bitcoin. Brasil, Austrália e Eslovênia são exemplos do grupo. (FOBE, 2016, p. 67-68)

Em um outro grupo de países, de forma contrária ao apresentado no parágrafo anterior, a autora afirma ter ocorrido discussões significativas quanto ao caráter monetário da criptomoeda. Países enquadrados neste grupo atingiram conclusões importantes sobre a utilização do bitcoin, tais como: "não possui curso forçado, ou que ele não rivaliza com a moeda oficial, ou, pelo contrário, que ele rivaliza com a moeda oficial". São exemplos desse grupo a Rússia, que decidiu proibir o bitcoin por considerá-lo um substituto monetário, e a Irlanda, que não o considerou como uma moeda legal do país (FOBE, 2016, p. 67-68).

Os países do terceiro e último grupo preocupam-se em estudar e monitorar as ocorrências envolvendo a criptomoeda, publicando os resultados de suas reuniões por meio de notas. Quanto às discussões realizadas, os países que representam esse grupo podem ser subdivididos em dois subgrupos, o primeiro deles realizaria discussões em âmbito legislativo, como Canadá e França, e o segundo em seus respectivos Bancos Centrais, como Reino Unido e Suécia (FOBE, 2016, p. 67-60).

Apesar da existência dos três posicionamentos citados supra, a serem adotados pelos países para lidar com as criptomoedas, não significa que seja preciso adotar apenas um, é o que Nicole Fobe chama de solução híbrida e exemplifica: "é o caso da Holanda, por exemplo, que adotou a publicação da nota de alerta, a inclusão do Bitcoin no rol de incidências tributárias específicas sem discutir seu caráter monetário" (FOBE, 2016, p. 69).

Diante da complexidade apresentada pelo tema, é normal que países utilizem os posicionamentos tratados acima conforme avancem no domínio do assunto. Sendo assim, em um primeiro contato com o bitcoin, seria comum o Banco Central emitir um alerta a esse respeito. Em seguida, pode-se imaginar que a moeda fosse incluída de forma pontual na legislação, tributando sua movimentação e/ou punindo condutas a ela relacionadas, mas sem demostrar preocupações quanto ao caráter monetário da moeda. Em um último estágio, a atenção estaria voltada à classificação jurídica do Bitcoin.

Em sua análise, Nicole Fobe observou que a maior parte dos países consultados utilizaram termos genéricos para se referir à regulamentação do bitcoin, tais como criptomoedas e moedas virtuais. Como dito anteriormente, o número de criptomoedas cresce a cada dia, regular/proibir apenas a moeda bitcoin poderia ser insuficiente diante dessa realidade, o uso de termos genéricos fez-se acertado (FOBE, 2016, p. 66). 
Em outro momento da pesquisa desenvolvida por Nicole Fobe, a classificação jurídica das criptomoedas foi analisada. Sete países classificam as criptomoedas como "mercadoria". Em seguida, os termos "ativo financeiro", "bem" e "serviço", foram empregados por três países cada. Na seção dos termos utilizados duas vezes, percebe-se "dinheiro", "instrumento financeiro", "meio de pagamento" e "moeda". Por fim, "e-money", "propriedade privada", "sistema de pagamento", "substituto monetário" e "unidade de conta" foram empregados por apenas um país cada. Seguindo esse mesmo raciocínio, afirma:

[...] pode-se perceber que a classificação jurídica do Bitcoin está longe de ser uma unanimidade. No entanto, como ele está sendo incorporado às ordens jurídicas majoritariamente pela via do Direito Tributário, a classificação tende a ser elaborada de acordo com os termos utilizados pela legislação tributária de cada país (FOBE, 2016, p. 71-72).

Não se pode deixar de abordar os países que proibiram a utilização de criptomoedas em seus territórios. Essa dura decisão foi aplicada por 11 países que, de forma unânime, valeram-se do direito penal para aplicar multas e até mesmo pena de prisão a quem descumprir a decisão. A medida foi implantada após discussões acerca do caráter monetário do bitcoin (FOBE, 2016, p. 72), desse modo, tais países encontram-se no último estágio de compreensão da criptomoeda, como afirmado anteriormente.

\subsection{LEGISLAÇÃo APLICÁVEL AO MUNDO DAS CRIPTOMOEDAS}

Diante das novidades apresentadas pelas criptomoedas, Nicole Fobe enumera cinco principais questões jurídicas que foram enfrentadas pelos países analisados:

[...] (a) se e como tributar as criptomoedas; (b) como qualificar juridicamente as criptomoedas; (c) como controlar atividades ilegais possibilitadas pelo 'anonimato' da internet; (d) como rastrear e identificar os usuários e suas transações; e (e) quando e como começar a trazer implicações jurídicas à utilização das criptomoedas (FOBE, 2016, p. 75).

Diante do interesse arrecadatório dos países, é comum que a primeira temática a ser tratada, acerca das criptomoedas, seja a tributação ou não das movimentações realizadas. Para isto, a classificação jurídica tratada no tópico anterior apresenta grande influência. Para exemplificar o exposto pode-se citar o ocorrido no Brasil que, com o fim de submeter as movimentações em criptomoedas à incidência do imposto de renda, a Receita Federal as classificou como ativo financeiro (FOBE, 2016, p. 75).

Nicole Fobe realizou importante análise acerca dos parâmetros tributários utilizados 
mundialmente. Esses parâmetros foram publicados pelo Financial Crimes Enforcement Network, pertencente ao Ministério da Fazenda dos Estados Unidos. Da análise, é possível auferir os seguintes pontos:

[...] (1) o Bitcoin é uma propriedade privada, não uma moeda de curso forçado (moeda legal), e portanto deve ser tributado como um bem de capital; (2) o lucro proveniente da venda de Bitcoins em troca de moeda de curso forçado está sujeito a impostos incidentes sobre ganhos de capital; (3) compras de bens e serviços realizadas em Bitcoin também devem ser contabilizadas como ganhos (de capital); (4) Bitcoins e outras criptomoedas obtidas por meio de mineração são reconhecidas como renda, sendo o seu valor computado em relação ao dia que a moeda foi 'adquirida'; (5) o equipamento utilizado na mineração de criptomoedas pode ser deduzido na categoria de bens de capital (FOBE, 2016, p. 76).

Nos países em que o uso das criptomoedas foi permitido, há uma clara preocupação com os tributos a serem recolhidos em função da movimentação dessas, em especial do bitcoin em razão de sua maior aceitabilidade e popularização. Posterior às implicações tributárias, é a preocupação com a licitude das transações que ganha força. Em razão das transações ocorrerem de forma anônima e da inexistência de um órgão fiscalizador, responsável por validar e controlar as transações em criptomoedas, essas podem ser facilmente utilizadas para movimentar valores adquiridos por meios ilícitos e realizar pagamentos por produtos de comercialização restrita ou proibida.

O uso da moeda em espécie sempre foi uma característica de quem, por algum motivo, precisou esconder recursos financeiros. Isso ocorre, pois a cada movimentação financeira bancária um registro é feito no sistema. Com a utilização do dinheiro em espécie, registros não são feitos, tornando quase impossível de rastrear e encontrar provas que confirmem as movimentações.

As criptomoedas unem a facilidade, presente nas movimentações bancárias virtuais, ao pseudoanonimato, típico da movimentação de dinheiro em espécie. Assim, tornaram-se um eficaz mecanismo para o cometimento de ilícitos. Importante observar que foi utilizado o termo pseudoanonimato para se referir às criptomoedas, isso ocorre em razão de todos os registros relacionados às criptomoedas serem gravados em um livro-razão de acesso público, o blockchain. Nas palavras de Fernando Ulrich (2014, p. 32):

O Bitcoin, por outro lado, é uma moeda descentralizada aberta que fornece um registro público de todas as transações. Lavadores de dinheiro podem tentar proteger seus endereços de Bitcoin e suas identidades, mas seus registros de transações serão sempre públicos e acessíveis a qualquer momento pelas autoridades. Lavar dinheiro por meio do Bitcoin, então, pode ser visto como uma empreitada muito mais arriscada do que usar um sistema centralizado como 
o Liberty Reserve. Ademais, diversas casas de câmbio de bitcoins têm tomado as medidas necessárias para estar em dia com as regulações e exigências das autoridades no que tange ao combate à lavagem de dinheiro. A combinação de um sistema de registro público (o livro-razão do Bitcoin, ou o blockchain) com a cooperação das casas de câmbio na coleta de informações dos usuários fará do Bitcoin uma via relativamente menos atrativa aos lavadores de dinheiro.

O autor tem razão ao afirmar que a cooperação das casas de câmbio somada à transparência dos registros públicos, diminuirá a atratividade para quem queira cometer ilícitos por meio das criptomoedas. No entanto, ao utilizar o sistema de chaves pública e privada, assim como o mixing fornecido por várias carteiras, a rastreabilidade das criptomoedas é reduzida drasticamente, garantindo o anonimato a quem queira dele se beneficiar.

\section{O DIREITO SUCESSÓRIO E A HERANÇA DIGITAL - ENQUADRAMENTO DAS CRIPTOMOEDAS E PROBLEMÁTICAS}

Com a morte, tem-se a abertura da sucessão e, conforme ver-se-á brevemente, há a transmissão automática dos bens aos herdeiros do falecido. Uma vez que o autor da herança possuía ativos em criptomoedas, tais bens incorporam-se ao espólio, fazendo parte da massa patrimonial, afinal, "Os bens tecnodigitais poderiam ser objeto de sucessão? Indubitavelmente sim, especialmente se o ativo tem caráter patrimonial" (LACERDA, 2016, p. 130).

Existe, portanto, a herança dos bens digitais - sendo, evidentemente, as moedas virtuais, um desses bens. Nathália de Campos Valadares (2019, p. 130) elucida que:

Herança virtual pode ser definida como o conteúdo que se encontra armazenado/ incluído em meios eletrônicos do falecido. Esses bens/direitos podem ser divididos em bens digitais de cunho patrimonial, existencial e patrimonial-existencial. Os bens/conteúdos que geram repercussões econômicas imediatas são os de cunho patrimonial. Entre eles, pode-se citar as milhas áreas e moedas virtuais eis que nítido o caráter econômico. O posicionamento majoritário é de que tais bens devem ser transmitidos aos herdeiros/legatários [...].

Não há dúvidas que existam outros tipos de bens digitais que devem compor o patrimônio sucessório, como as milhas aéreas e até mesmo conteúdos de redes sociais. Sobre as moedas virtuais, Bruno Torquato Zampier Lacerda é categórico ao reconhecer o caráter patrimonial destas, caso contrário, não estariam sendo regulamentadas pelos bancos centrais de diversos países, e defende a necessidade de serem transmitidas pelo direito de saisine aos herdeiros de seu titular (LACERDA, 2016, p. 132).

Entretanto, apesar de poder ser óbvia a constatação de que as criptomoedas fazem parte de um montante ativo a ser herdado pelos herdeiros do falecido, as implicações práticas deste 
tipo de patrimônio podem ser bem mais complexas do que o mero direito sucessório. Inclusive pelo fato de não haver regulamentação no Brasil, o que destaca Bruno Torquato Zampier Lacerda (2016, p. 193):

Ante a ausência de regulamentação legislativa específica do tema no Brasil, até o presente momento, e da não confecção, na maior parte dos casos, de testamentos comuns ou digitais, a questão que se coloca é: como devem ser resolvidos os problemas crescentes ligados ao destino dos ativos digitais. Há uma verdadeira lacuna legal, que dificilmente poderá ser preenchida pela simples aplicação dos tradicionais recursos previstos no art. $4^{\circ}$ da Lei de Introdução às Normas do Direito Brasileiro (LINDB).

Tal ausência de regulamentação remonta à "insegurança jurídica [no Brasil], na medida em que não se tem regulamentação específica e há controvérsias em relação à aplicação (ou não) das regras clássicas de sucessão à herança digital. Poucos ainda são os julgados a respeito" (MENDES; FRITZ, 2019, p. 191).

Conforme mencionado pelo autor, diante das lacunas legislativas e da novidade temática, passa-se à abordagem das principais problemáticas atinentes à herança de moedas digitais.

\subsection{A LeGítima COMO AFRONTA À AUTONOMIA PRIVAdA E A TRANSMISSÃo DE CRIPTOMOEDAS}

No direito das sucessões, um instituto bastante controverso é o da legítima. A legítima, em termos bem gerais, consiste na manutenção de, pelo menos, metade do patrimônio do autor da herança, reservando-o aos herdeiros legítimos e necessários ${ }^{5}$ (BRASIL, 2002).

Dessa forma, não é permitido que uma pessoa disponha de seu patrimônio, ainda em vida, de modo que este diminua em mais de cinquenta por cento do total, que é o montante protegido pela legítima. Aqui, cuida-se para evidenciar que o direito à herança surge somente no momento da morte da pessoa que detém o patrimônio, de modo que não é possível, de acordo com o Código Civil, estabelecer limites contratuais ao patrimônio da pessoa: "Art. 426. Não pode ser objeto de contrato a herança de pessoa viva" (BRASIL, 2002).

É o que se chama na doutrina de pacta corvina. Todavia, ressalta-se o dispositivo legal do códex privado que impossibilita a doação que exceda a parcela da legítima: "Art. 549. Nula é também a doação quanto à parte que exceder à de que o doador, no momento da liberalidade, poderia dispor em testamento" (BRASIL, 2002). Nesse sentido, Flávio Tartuce (2018, p. 726) indica que

Segundo o art. 549 do CC/2002, é nula a doação quanto à parte que exceder o limite de que o doador, no momento da liberalidade, poderia dispor em testamento. Essa doação, que prejudica a legítima, a quota dos herdeiros

5 Art. 1.846. Pertence aos herdeiros necessários, de pleno direito, a metade dos bens da herança, constituindo a legítima. 
necessários, correspondente a 50\% do patrimônio do disponente, é denominada doação inoficiosa.

Pretende-se, assim, preservar a unidade familiar, ainda após a morte, resguardando aos herdeiros o patrimônio do ascendente, descendente ou cônjuge/companheiro - que são os herdeiros necessários. (BRASIL, 2002). Sobre o assunto, remonta à antiguidade as tentativas de utilizar da sucessão para dar a continuidade ao seio familiar. Fustel de Coulanges (2009, p. 86), indica que

Para ter uma ideia verídica da herança entre os antigos, não se deve imaginar uma riqueza que passa de mão em mão. A riqueza é imóvel, como o lar e o túmulo a que está ligada. $\mathrm{O}$ homem é que passa. O homem é que, à medida que a família atravessa suas gerações, chega na hora marcada para continuar o culto e cuidar das terras.

Destarte, até a contemporaneidade se vislumbra o caráter de proteção e de continuidade à família através do direito sucessório, o que pode ser confirmado no próprio instituto da legítima, conforme exposto.

Entretanto, a imposição de se respeitar a legítima, ou seja, de não poder dispor livremente de um patrimônio que é exclusivamente da pessoa, também pode ser interpretado como uma afronta à autonomia privada, sendo o direito de dispor da própria fortuna um ato de última vontade e de expressão do individualismo (MAXIMILIANO, 1964, p. 27).

Nessa seara, compreende-se adequado trazer o conceito de autonomia privada, que é explicitada por Pietro Perlingieri (2002, p. 17) como

[...] pode-se entender por 'autonomia privada', em geral, o poder reconhecido ou concedido pelo ordenamento estatal a um indivíduo ou a um grupo, de determinar vicissitudes jurídicas [...] como consequência de comportamentos - em qualquer medida - livremente assumidos.

Com o novo paradigma do Estado Democrático de Direito, a autonomia privada passa a ser pilar nas relações privadas, inclusive para a efetivação do princípio da dignidade da pessoa humana, garantido na carta constitucional, por possibilitar que o indivíduo tenha liberdade na autodeterminação dos atos de sua vida civil.

Consoante ao exposto, Gabriela Mascarenhas Lasmar reconhece a proteção conferida pela Constituição de 1988, especialmente em seu artigo 226, à família pelo Estado. Além do mais, defende que a dignidade da pessoa humana é um dos fundamentos da República Federativa do Brasil, presente no artigo $1^{\circ}$, inciso III, da Constituição. Ao tratar do Código Civil de 2002, a autora defende que este precisa deixar de lado a visão patrimonialista de seu antecessor, o Código Civil de 1916, para aplicar uma visão em prol da pessoa humana em conformidade com os dispositivos constitucionais (LASMAR, 2019, p. 37). Na prática, não são poucas as tentativas de burlar as regras sucessórias impostas com a legítima: doações em vida e criação de pessoas jurídicas 
familiares são exemplos corriqueiros, e a utilização de criptomoedas como parte do patrimônio da pessoa é uma nova forma de, potencialmente, esquivar de tal engessamento legal. Sobre o tema, Gabriela Mascarenhas Lasmar aponta, corretamente, que, "Tendo em vista as rápidas e constantes transformações ocorridas no Brasil faz-se necessário repensar o instituto da legítima no direito sucessório brasileiro" (LASMAR, 2019, p. 39).

Conforme dito, nenhuma pessoa pode, em vida, alienar ou doar seu patrimônio em mais do que metade da totalidade dos bens - para preservar a legítima. Todavia, com a compra e venda de criptomoedas essa pessoa está, em realidade, realizando transações com o próprio patrimônio (como uma prática comum do mercado de ações).

Imagine-se, então, a situação de que o indivíduo coloca parte considerável de seu patrimônio em moedas digitais, inclusive excedendo a cota de legítima. Isso estaria dentro da legalidade, pois ocorreu uma sub rogação dos bens da pessoa, de dinheiro físico, para o dinheiro digital. Nessa situação, como ficaria a questão da herança caso o proprietário dessa wallet falecesse, estando, assim, com toda ou considerável parte dos seus bens em criptomoedas? É nítida que a legítima fora prejudicada.

A título exemplificativo, Marcelo Trussardi Paolini e Maria Paula Meirelles Thomaz de Aquino (2019, p. [1]) indicam dois casos inesperados:

Nada obstante, o tratamento jurídico brasileiro sobre o tema é, ainda, bastante escasso, o que exige de seus investidores certas condutas que visem assegurar e garantir o direito de transmissão aos herdeiros, evitando os riscos decorrentes da ausência de proteção do Estado.

A título de exemplo, e conforme amplamente divulgado pela imprensa, o caso de Gerald Cotten, fundador da prestigiada corretora canadense de criptomoedas QuadrigaCX, é interessante para ilustrar os reais problemas decorrentes da ausência de um planejamento sucessório na seara das criptomoedas.

Em dezembro de 2018, o Sr. Cotten, o único detentor da senha para acesso aos ativos digitais da empresa, faleceu repentinamente. Diante da impossibilidade de recuperação da senha através do sistema, e pela ausência de planejamento, a corretora sofreu uma perda de US\$ 190 milhões armazenados, prejudicando em torno de 115 mil clientes.

Situação semelhante também ocorreu com um dos investidores pioneiros em criptomoedas, Matthew Moody, que morreu em um acidente de avião e não cedeu suas senhas de acesso à carteira digital a ninguém. Novamente, todo o investimento realizado se tornou permanentemente inacessível.

Nos casos acima, não é possível saber, com as informações superficiais, se ocorreu uma extrapolação da legítima. Mas imagine-se que sim: dessa forma, além da cota dos herdeiros não ter sido respeitada, tais herdeiros quiçá poderão ter acesso ao patrimônio, uma vez que não foi possível recuperar a chave de acesso.

Tem-se, então, nova possibilidade perante às criptomoedas: além da possível inobservância da legítima, a alteração na ordem de vocação hereditária - como se verá em tópico infra. Em ambas as situações, verifica-se que a autonomia privada do autor da herança fora respeitada, qual seja a 
de manter seus bens em meio digital. É claro que é possível que, mesmo com a sub rogação do patrimônio em tais bens, o de cujus ainda assim quisesse que seus herdeiros recebessem. Nesse sentido, para resguardar tanto a autonomia do falecido, quanto a última vontade de deixar a herança, é

[...] imprescindível que o investidor elabore um plano claro e objetivo de transmissão das criptomoedas, e, especialmente, que informe aos herdeiros onde localizá-las, quais as plataformas/sistemas utilizados para o seu armazenamento e como se dará seu acesso técnico (acesso a chaves e senhas) (PAOLINI; AQUINO, 2019, p. [1]).

Diante do exposto acerca da legítima, passa-se agora à explanação sobre a ordem de vocação hereditária e a herança digital.

\subsection{A (NÃo)RASTREabiLIDAde COMO POSSIBILIDAde DE MUTAÇÃo NA ORDEM DE VOCAÇÃo HEREDITÁRIA}

Conforme previamente abordado, o cônjuge/companheiro, os descendentes e os ascendentes compõem os herdeiros legítimos e necessários. Sobre a ordem de vocação hereditária, o códex brasileiro indica, nos artigos 1.829 a 1.844, que a ordem de chamamento é dos descendentes (com direito concorrencial ao cônjuge, a depender do regime de bens do casamento), dos ascendentes (igualmente com concorrência do cônjuge), do cônjuge sozinho em terceira posição e, por fim, dos colaterais até o quarto grau (BRASIL, 2020). Essa ordem é imperiosa, principalmente no que tange à sua combinação para com a cota da legítima - já supra explanada.

Nesse sentido, conforme dito, a herança de moeda digital é realidade. Todavia, uma de suas características tem sido motivo de diversos problemas no assunto. Nathália de Campos Valadares (2019, p. 131-132) aponta que, como

[...] as moedas virtuais têm tomado no cenário econômico e jurídico, a Revista Época (2018) trouxe interessante reportagem sobre esse bem digital. Nessa oportunidade, retratou o caso de um americano que tinha conhecimento de que seu filho possuía moedas virtuais, entretanto, com o falecimento dele, não conseguiu de forma alguma ter acesso a elas.

'Há cinco anos, Matthew Moody, de 26 anos, morreu em um acidente de avião quando sobrevoava um cânion em Chico, na Califórnia. Seu pai, Michael Moody, sabia que o filho estava minerando bitcoins - que hoje valem milhares de dólares cada um - , mas não tinha ideia quantos ou como encontrá-los. Michael Moody passou os últimos três anos procurando as respostas. Meu filho foi uma das primeiras pessoas a buscar bitcoins. Ele usava seu computador de casa para minerar bitcoins, quando isso era possível, e tinha alguns, disse Moddy, um engenheiro de softwares aposentado. A natureza descentralizada e desregulada do bitcoin significa que, sem as senhas para ter acesso à carteira digital do seu filho, 
instalada no blockchain.info, Moody não tem como ter acesso a nenhum recurso.

No caso acima, a situação foi de morte não esperada, de modo que a senha de acesso não fora repassada para ninguém. Porém, há ainda a possibilidade de o detentor de quantia em criptomoeda não querer que a chave seja acessível aos seus herdeiros, visto que "O grande problema [...] é a extrema dificuldade de se obter a chave de acesso e/ou saber onde estão armazenadas sem que tais informações sejam repassadas pelo proprietário das moedas" (VALADARES, 2019, p. 132).

Veja-se, pois, a seguinte situação: uma pessoa detentora de considerável montante de criptomoedas falece, deixando, então, tal patrimônio digital. Contudo, a key dessa wallet conceitos explicados supra - fora deixada para alguém que não seu herdeiro necessário, mas sim um terceiro. Para resolver tal questão, Nathália de Campos Valadares defende ser necessário incluir cláusula testamentária informando senha e login aos herdeiros, quando tratar-se de bens virtuais patrimoniais, caso contrário, dificilmente os herdeiros terão acesso a estes, colocando em risco sua transmissibilidade. Pontua a autora que isto é necessário em razão dos empecilhos quanto à rastreabilidade dos bens virtuais que, como visto, não ocorre conforme parâmetros de bens comuns (VALADARES, 2019, p. 132).

Entretanto, não parece ser tão simples a solução, visto que, apenas nessa seção já se citou duas situações que iriam além da mera cláusula testamentária: a primeira é a da morte inesperada ou súbita, quando a pessoa até tem a intenção de deixar os bens digitais para seus herdeiros, contudo ainda não teve o tempo de fazer o testamento, tampouco de repassar a key; a outra é ainda mais complexa, pois decorre da opção feita pelo autor da herança de não deixar a chave de acesso aos seus herdeiros, por não querer que estes tomassem para si o patrimônio deixado em criptomoedas.

Dessa forma, verifica-se não só a atuação plena da autonomia privada do de cujus, como também o possível afronte à ordem de vocação hereditária e até mesmo a extrapolação da legítima, resultando, assim, em outra problemática: a inobservância do princípio milenar de Droit de Saisine.

\subsection{O PRINCÍPIO DE DROIT de SAISINe E AS CRIPTOMOEDAS: AFRONTA AO PRINCíPIO OU SOLUÇÃo PARA AUTONOMIA?}

O princípio de Droit de Saisine determina que automaticamente, com a morte, o patrimônio do autor da herança imediatamente passa aos seus herdeiros ${ }^{6}$ (BRASIL, 2020). O objetivo por trás do princípio da Saisine remonta às épocas antigas. É o que defende Calânico Sobrinho Rios, ao afirmar que esse princípio foi criado para que não se aplicasse a regra feudal, que, com a morte dos servos, defendia a transmissão dos bens desses aos seus respectivos senhores feudais, prejudicando os herdeiros dos primeiros (RIOS, 2018, p. 203).

Complementando que, evidentemente, "pela inclusão feita no artigo 1.784, os herdeiros

6 Indica o Código Civil em seu artigo 1.784: “Aberta a sucessão, o domínio e a posse da herança transmitem-se, desde logo, aos herdeiros legítimos e testamentários". 
necessários, descendentes, ascendentes e cônjuge supérstite, já são donos e possuidores do acervo deixado pelo findo" (RIOS, 2018, p. 203).

O Droit de Saisine é um bom exemplo da ausência de autonomia privada do autor da herança, uma vez que, quando da sua morte, independentemente de sua vontade pessoal - ainda que conhecida em vida pelos seus entes e amigos -, seu patrimônio será transmitido aos seus herdeiros, observando a ordem de vocação hereditária e a parcela da legítima, mesmo se presente um testamento (pois este deverá observar, também, tais imposições).

Todavia, conforme já explanado nas seções acima, concernente às problemáticas atreladas à herança das moedas digitais, o princípio milenar da automação e imediaticidade na transmissão do patrimônio pode sofrer com as novas práticas digitais.

Sobre isso, Nathália de Campos Valadares complementa, afirmando que o problema reside na necessidade do proprietário de bens digitais compartilhar informações como login e chave de segurança com seus familiares para que, diante de seu falecimento, possam realizara a transmissão do patrimônio. O não compartilhamento de tais informações prejudica a transmissão bens e direitos, que se tornará quase impossível (VALADARES, 2019, p. 144).

Tal situação, em realidade, trata de uma quebra de paradigma no contexto do direito sucessório não só brasileiro, mas mundial. Isso porque sempre se considerou que o patrimônio automaticamente passasse aos herdeiros, nunca ficando um patrimônio sem titularidade - e, ainda nos casos de herança vacante ou jacente, há destinação do patrimônio no fim das contas. É o que indicam Ana Maria Alves Machado e Hugo Rios Bretas, ao afirmar que aos herdeiros transmite-se o patrimônio do falecido no momento de sua morte, não podendo ficar a herança sem um titular, entendimento consagrado pelo princípio de Saisine (MACHADO; BRETAS, 2019, p. 106).

Sobre a transmissibilidade, há o projeto de Lei 4099/12, do deputado Jorginho Mello (BRASIL, 2012a), que visa alterar o art. 1.788 da Lei $n^{\circ} 10.406$, de 10 de janeiro de 2002, o Código Civil. A proposta do parlamentar foi feita no sentido de acrescentar ao art. 1788 do referido códex o parágrafo único dispondo que "serão transmitidos aos herdeiros todos os conteúdos de contas ou arquivos digitais de titularidade do autor da herança" (ALMEIDA, 2017, p. 77).

Ademais, há também o projeto de Lei 4847/12, do deputado Marçal Filho, que acrescenta o Capítulo II-A e os artigos 1.797-A a 1.797-C ao Código Civil, trazendo a temática da herança digital (BRASIL, 2012b).

As propostas parecem interessantes e determinadas em resolver a questão da transmissibilidade, obedecendo, assim, ao que preceitua o princípio da saisine. Entretanto, parecem propostas ingênuas uma vez que não se atentam aos limites de tal transmissão - como no caso das criptomoedas, em que a rastreabilidade do ativo pode ser, praticamente, impossível ou, ainda, nos casos em que não se tem acesso à chave da carteira.

Em relação aos bens tecnodigitais de natureza patrimonial - como perfis privados em redes sociais, fotos, e-mails, etc - Bruno Torquato Zampier Lacerda já indica que há, neles, uma exceção ao Droit de Saisine: "Já quanto aos bens tecnodigitais existenciais, como afirmado anteriormente, não seria possível, como regra a sua sucessão, não se aplicando aqui o princípio de 
saisine, previsto no art. 1.784, CC” (LACERDA, 2016, p. 172).

É plenamente compreensível que as criptomoedas integrem uma parte dos bens digitais patrimoniais - e não existenciais ${ }^{7}$. Não há dúvidas que, uma vez que as moedas digitais tenham um ativo financeiro e um valor patrimonial considerável, deveriam configurar como bens herdados na sucessão, a exemplo similar das milhas aéreas.

Porém, diferentemente das milhagens, as criptomoedas contam com a dificuldade no rastreio e com a possibilidade de se entregar a chave de acesso à alguém que não um herdeiro necessário - e mais, sem que ninguém saiba quem é a pessoa com o acesso, tampouco onde ela se encontra.

Destarte, "Tratar um fenômeno novo à luz da centenária construção do direito de saisine não parece ser a melhor solução" (LACERDA, 2016, p. 194). Evidentemente que se deve encontrar uma solução, uma vez que as moedas digitais são ativos patrimoniais e que o direito sucessório determina que o patrimônio do de cujus seja transmitido aos herdeiros necessários preservando a legítima de cinquenta por cento do patrimônio.

Bruno Torquato Zampier Lacerda (2016, p. 197) indica que boas soluções decorrem da tradição incorporada pelo intérprete ao longo de sua vida, assim, a inexistência desta tradição digital no intérprete causará a aplicação do princípio de saisine, em que se concede a ultrapassada visão de transmissibilidade a qualquer tipo de bem.

De tal maneira, é urgente que o direito sucessório brasileiro se (re)posicione quanto às regras de transmissibilidade, uma vez que há novas tecnologias que desafiam a ordem tradicional e historicamente imposta, demonstrando que não é mais possível se manter com os mesmos posicionamentos e regulamentações antigas - prática comum no direito das sucessões, que tende a se manter o mesmo ao longo das mudanças temporais -, tampouco adianta apresentar soluções ingênuas, que já nascem ultrapassadas perante aos desafios das heranças dos bens tecnodigitais.

\section{CONSIDERAÇÕES FINAIS}

Ao criar a criptomoeda bitcoin, Satoshi Nakamoto deu origem a um importante avanço tecnológico, que restará marcado na história da humanidade ao lado de outros inventos imprescindíveis à população. Sua perspicácia ao desenvolver uma moeda cuja criação e controle independem da vontade estatal, permite que a população utilize uma moeda pura, interligada aos incentivos do mercado e desvinculada de interesses partidários.

Como visto, cada nação trata das criptomoedas de um modo e situam-se em uma fase distinta de aplicação e análise do tema. Alguns países optaram por proibir sua utilização, enquanto outros a permitiram. Da mesma forma, há aqueles que analisaram o tema com maestria, enquanto outros não se deram ao trabalho.

O surgimento das criptomoedas desencadeou importantes consequências jurídicas. Nos




países que permitiram o seu uso, em sua maioria, a regulamentação se deu por meio do direito tributário, em razão dos interesses arrecadatórios dos países. Já nos que as proibiram, recorreu-se ao direito penal para tanto.

Conforme pretendia-se, restou-se demonstrado a obsolescência do direito sucessório frente às novas realidades contemporâneas. As criptomoedas, quanto herança digital, são apenas um pontapé no mundo novo de bens a serem transmitidos por sucessão que não se adequam às normas dantes estabelecidas.

É urgente a reflexão sobre a legislação privada de ordem sucessória, uma vez que não é mais possível adequar velhos princípios e leis, às novas ordens de relação dos serem humanos para com seus bens.

Ademais, é importante reavaliar institutos como a legítima e princípios seculares que versam sobre a transmissibilidade imediata dos bens, uma vez que - evidentemente -, tais institutos não acompanham as modificações de ordem tecnológica e também de ordem social, como a concepção, antes impossível, de que nem sempre o autor da herança pretende deixar seus bens para seus herdeiros necessários.

Para que as criptomoedas saiam de um estigma de serem usadas para burlar legislações e sistemas engessados, é preciso encará-las como, sim, um desafio, mas principalmente como o futuro que irá permear diversas relações jurídicas.

Não se pode temer as porvindouras situações que a tecnologia traz e, com isso, afastar da realidade e manter uma ordem jurídica obsoleta. Não, em verdade é preciso pesquisar, refletir, debater e, sim, cambiar ordens que são mutáveis, de acordo com as necessidades fáticas e que refletem uma nova concepção jurídica - tal como está acontecendo com o direito sucessório.

\section{REFERÊNCIAS}

ALMEIDA, Juliana Evangelista de. A tutela jurídica dos bens digitais após a morte: análise da possibilidade de reconhecimento da herança digital. 2017. Tese (Doutorado em Direito) Universidade Católica de Minas Gerais, Belo Horizonte, 2017.

BRANDÃO, Carlos Antônio Leite. A transdisciplinaridade. In: PAULA, João Antonio (org.). A transdisciplinaridade e os desafios contemporâneos. Belo Horizonte: Editora UFMG, 2008. p. ini-fin.

BRASIL. Câmara dos Deputados. PL 4099/2012. Altera o art. 1.788 da Lei no 10.406 , de 10 de janeiro de 2002, que "institui o Código Civil”. Brasília: Câmara dos Deputados, 2012a.

BRASIL. Câmara dos deputados. PL 4847/2012. Acrescenta o Capítulo II-A e os arts. 1.797A a 1.797-C à Lei no 10.406, de 10 de janeiro de 2002. Brasília: Câmara dos Deputados, 2012b. Disponível em: http://www.lexml.gov.br/urn/urn:lex:br:camara.deputados:projeto. lei;pl:2012-12-12;4847. Acesso em: 15 jul. 2020.

BRASIL. Lei 10.406, de 10 de janeiro de 2002. Institui o Código Civil. Diário Oficial da União, 
Brasília, 11 jan. 2002.

BRITO, Jerry; CASTILLO, Andrea. Bitcoin: a primer for policymakers. 2. Ed. [S.l.]: Mercatus Center, 2013.

COINLIB. Coins. 2020. Disponível em: https://coinlib.io/coins. Acesso em: 11 jun. 2020.

FOBE, Nicole Julie. O Bitcoin como moeda paralela - uma visão econômica e a multiplicidade de desdobramentos jurídicos. 2016. Dissertação (Mestrado) - Escola de Direito de São Paulo da Fundação Getulio Vargas, São Paulo, 2016.

FUSTEL DE COULANGES. Numa Denis. A cidade antiga: estudo sobre o culto, o direito e as instituições da Grécia e de Roma. Tradução de Roberto Leal Ferreira. São Paulo: Martin Claret, 2009.

LACERDA, Bruno Torquato Zampier. A tutela dos bens tecnodigitais: possíveis destinos frente à incapacidade e morte do usuário. 2016. Dissertação (Mestrado em Direito) - Pontifícia Universidade Católica de Minas Gerais, Belo Horizonte, 2016.

LASMAR. Gabriela Macarenhas. Análise crítica sobre o instituto da legítima no Brasil. In: RIOS, Calânico Sobrinho; LASMAR, Gabriela Mascarenhas; RODRIGUES JÚNIOR, Walsir Edson (coord.). Relações familiares e o direito sucessório. Belo Horizonte: Conhecimento Livraria e Distribuidora, 2019. p. ini-fin.

MACHADO, Ana Maria Alves; BRETAS, Hugo Rios. Ensaios sobre (in)congruência da usucapião entre herdeiros. In: RIOS, Calânico Sobrinho; LASMAR, Gabriela Mascarenhas; RODRIGUES JÚNIOR, Walsir Edson (coord.). Relações familiares e o direito sucessório. Belo Horizonte: Conhecimento Livraria e Distribuidora, 2019. p. ini-fin.

MAXIMILIANO, Carlos. Direito das sucessões. Rio de Janeiro: Freitas Bastos, 1964.

MENDES, Laura Schertel Ferreia; FRITZ, Karina Nunes. Case report: corte Alemã reconhece a transmissibilidade da herança digital. RDU, Porto Alegre, v. 15, n. 85, p. 188-211, jan./fev. 2019.

NAKAMOTO, Shatoshi. Bitcoin: um sistema de dinheiro eletrônico peer-to-peer. 2008. Disponível em: https://bitcoin.org/bitcoin.pdf. Acesso em: 9 jun. 2020.

PAOLINI, Marcelo Trussardi; AQUINO, Maria Paula Meirelles Thomaz de. Planejar ou perder: o impacto das criptomoedas no direito sucessório. Brasília: Anoreg, 2019. Disponível em: https:/www.anoreg.org.br/site/2019/08/30/artigo-planejar-ou-perder-o-impacto-dascriptomoedas-no-direito-sucessorio-por-marcelo-trussardi-paolini-e-maria-paula-meirellesthomaz-de-aquino/. Acesso em: 9 jun. 2020.

PERLINGIERI, Pietro. Perfis do direito civil. Tradução de Maria Cristina de Cicco. 3. ed. Rio de Janeiro: Renovar, 2002.

RIOS, Calânico Sobrinho. As (des)vantagens da legítima: num breve transitar pela análise econômica do direito. In: DIVINO, Sthéfano Bruno Santos; ZANETTI, Matheus Felipe Moreira (org.). Reflexões de direito civil contemporâneo. Porto Alegre, RS: Editora Fi, 2018. p.187212. Disponível em: https://www.editorafi.org/406direito. Acesso em: 10 jun. 2020. 
TARTUCE, Flávio. Manual de direito civil: volume único. 8. ed. Rio de Janeiro: Forense; São Paulo: MÉTODO, 2018.

ULRICH, Fernando. Bitcoin: a moeda na era digital. São Paulo: Instituto Ludwig von Mises Brasil, 2014.

VALADARES, Nathália de Campos. Herança digital: a morte e a (in)transmissibilidade de conteúdos digitais. In: RIOS, Calânico Sobrinho; LASMAR, Gabriela Mascarenhas; RODRIGUES JÚNIOR, Walsir Edson (coord.). Relações familiares e o direito sucessório. Belo Horizonte: Conhecimento Livraria e Distribuidora, 2019. p. ini-fin.

Como citar: BARBOSA, Eduardo Henrique de Oliveira; LIMA, Taisa Maria Macena de; ALENCAR, Maria Clara Souza. A era das criptomoedas e o Direito Sucessório: reflexos na (in) transmissibilidade do patrimônio. Scientia luris, Londrina, v. 25, n. 3, p. 49-70, nov. 2021. DOI 10.5433/21788189.2021v25n3p49. ISSN: 2178-8189.

Recebido em 2020-08-19

Aprovado em 2021-09-26 